\title{
Eancacão \\ @๑Ðఠ $O$ enfoque sistêmico dialético e a organização dos conteúdos da Química: reflexões didático-filosóficas
}

\author{
Isauro Beltrán Núñez* \\ Sandro Damião Ribeiro da Silva**
}

Resumo: Neste artigo, apresentam-se fundamentos de uma proposta para a organização dos conteúdos de um tema da disciplina Química Geral sob as exigências do enfoque sistêmico-dialético do tipo genético. Essa forma de organização dos conteúdos toma como pressupostos filosóficos o materialismo dialético e histórico e a categoria de sistema, como estruturante e integrativa. É uma proposta didática que pode contribuir para o desenvolvimento teórico do pensamento dos estudantes no contexto da educação química. Por sua vez, constituise em um método do pensamento para a compreensão do conteúdo como um sistema complexo em desenvolvimento, mostrando um potencial para a transferência das aprendizagens, se considerada sua natureza teórica e geral.

Palavras-chave: Enfoque sistêmico-dialético. Conteúdos. Química Geral.

\section{The dialectic systemic approach and the organization of Chemistry contents: didactic-philosophical reflections}

\begin{abstract}
In this article, we present the fundamentals of a proposal for the organization of General Chemistry contents under the requirements of the dialectical systemic approach of genetic type. This form of content organization takes as philosophical presuppositions the dialectical and historical materialism and the category of system, as being structuring and integrative. It is a didactic proposal that can contribute to the theoretical development of student thinking in the context

\footnotetext{
* Doutor em Pedagogia pela Universidade de Havana, Cuba (UH). Professor Titular Centro Educação da Universidade Federal do Rio Grande do Norte (UFRN). E-mail: isaurobeltran@yahoo.com.br ORCID: https://orcid.org/0000-0003-3224-4694

${ }^{* *}$ Doutorando em Geografia pela Universidade Federal do Rio Grande do Norte (UFRN). Email: sandro@comperve.ufrn.br
} 
of Chemistry education. In turn, it establishes a method of thought for the understanding of content as a complex system in development, showing a potential for the transference of learning, considering its theoretical and general nature.

Keywords: Dialectical systemic approach. Contents. General Chemistry.

\section{El enfoque sistémico dialéctico y la organización de los contenidos de la Química: reflexiones didáctico folosóficas}

Resumen: En este artículo se presentan fundamentos de una propuesta para la organización de los contenidos de un tema de la disciplina Química General bajo las exigencias del enfoque sistémico dialéctico del tipo genético. Esta forma de organización de los contenidos toma como presupuestos filosóficos el materialismo dialéctico e histórico y la categoría de sistema, como estructurante e integrativa. Es una propuesta didáctica que puede contribuir con el desarrollo teórico del pensamiento de los estudiantes en el contexto de la educación química. A su vez se instituye en un método del pensamiento para la comprensión del contenido como un sistema complejo en desarrollo, mostrando un potencial para la transferencia de los aprendizajes, si se considera su naturaleza teórica y general.

Palabras clave: Enfoque sistémico dialéctico. Contenidos. Química General.

\section{Introdução}

A seleção e a organização do conteúdo de ensino são um tema de grande importância que faz parte dos estudos e das pesquisas na área da Didática das Ciências e do ensino de Química em específico (IZQUIERDO, 2005; NÚÑEZ, 2009; POZO; GÓMEZ CRESPO, 2009; CAAMAÑO, 2006). Essa importância está relacionada ao fato de a organização dos conteúdos influenciar a qualidade da aprendizagem dos estudantes, uma vez que se articula com a abordagem metodológica que orienta o ensino no contexto da educação científica dos estudantes. 
No caso do ensino de Química, Galagovsky (2005) explica a forma tradicional de se organizar um currículo como um processo de passos, no qual os teóricos chegam a consensos, retirando alguns tópicos e incluindo outros. Esse processo, para a autora, conduz à preservação da "tradição", sem tentar enfrentar os mais numerosos problemas subjacentes, de um modo mais fundamental. De acordo com a autora, "refazer o currículo de Química tem-se tornado um sério problema e uma tarefa onde oficialmente se possa fugir da tradição de como fazê-lo, que também tem sido autorreferente nos últimos tempos" (GALAGOVSKY, 2005, p. 14). Dessa forma, segundo essas reflexões, faz-se necessária a busca de novas alternativas para superar a visão do conhecimento químico dos programas tradicionais.

Na opinião de Núñez (2009), a problemática dos conteúdos, sua seleção e sua organização devem levar a um novo olhar dessa categoria didática do programa da Química Geral, de forma a: a) organizar o conteúdo de modo que, sem aumentar seu volume, ou seja, supersaturar de informações o currículo, sejam trabalhados os conhecimentos necessários para desenvolver o ensino da Química na Educação Básica; b) garantir a formação das habilidades gerais (em estreita união com o sistema de conhecimentos) e os métodos do pensamento que permitam aplicar, de modo independente e criativo, os conhecimentos em situações típicas, novas e obter novos conhecimentos; e c) potencializar a formação de valores e atitudes como finalidade-chave da educação em Química.

As pesquisas desenvolvidas por P. Ya. Galperin e V. V. Davidov, na opinião de Reshetova (2004), mostraram que a estruturação dos conteúdos de uma disciplina não é uma questão secundária, mas um problema essencial do ensino e da educação. Dessas pesquisas, derivase a necessidade de substituir a estruturação dos conteúdos que favorecem o pensamento empírico em novos princípios orientados a favorecer a formação do pensamento teórico, como característica da ciência contemporânea. O pensamento científico-teórico é uma das 
exigências que a sociedade moderna impõe ao homem, e, portanto, a escola tem a responsabilidade de contribuir para sua formação. Esse tipo de pensamento exige que o estudante se oriente não só em relação ao conteúdo do conceito, mas também às formas de estruturação do conhecimento, que representam formas de generalização teórica. (DAVIDOV, 1986; RESHETOVA, 2002).

Neste artigo, apresentamos e discutimos os pressupostos de uma proposta de organização dos conteúdos do tema "Estrutura e propriedades físicas das substâncias e dos materiais da Química Geral" como uma possibilidade de integração dialética sistêmica intradisciplinar dos conteúdos desse tema, o que pode levar a importantes contribuições para o desenvolvimento do pensamento teórico e, consequentemente, da educação científica dos estudantes. A discussão fundamenta-se nos pressupostos da filosofia do materialismo dialético e histórico e nas concepções sobre aprendizagem desenvolvidas na Escola Históricocultural de L. S. Vigotsky.

\section{Um enfoque integrador dos conteúdos - estruturação sistêmica dialética dos conteúdos}

Sob o enfoque da Didática Desenvolvimentista (ZILBERSTEIN; OLMEDO, 2015; ADDINE, 2004; NÚÑEZ, 2009), existe uma literatura dedicada à análise dos princípios fundamentais que refletem a orientação sistêmica dialética do objeto de estudo e dos conceitos fundamentais com os quais se pode explicar a complexidade desse objeto. Essa perspectiva sistêmica fundamenta-se nos princípios do materialismo dialético e histórico e, nela, destaca-se um conjunto de princípios e ideias de sistematicidade dos objetos que são estudados e expressos por meio do conceito de sistema, o que possibilita aos estudantes desenvolverem uma orientação sistêmica, dialética e generalizada do objeto de estudo (RESHETOVA, 2004; NÚNEZ; GONZÁLEZ, 1996; SALMINA, 1988). 
Na dialética do materialismo dialético e histórico, considera-se que compreender um objeto significa seu estudo em toda a sua diversidade e variedade dos nexos e mediações, em contraste com a metafísica, que entende os fenômenos como entidades separadas (CHEPTULIN, 2004). O pensamento dialético procura as diversas e complexas interações, as causas e os efeitos que descrevem o desenvolvimento dos fenômenos da natureza, da sociedade e do pensamento. Dessa forma, uma tarefa da análise dialética é encontrar as conexões essenciais de todos os aspectos, de todas as formas e de todas as tendências dos fenômenos. Como explica Kopnin (1966), o conhecimento dos fenômenos da natureza é também resultado do estabelecimento de relações de conexões essenciais entre as partes do fenômeno, que ganha significado no contexto do todo.

Os conteúdos que respondam a um processo de ensinoaprendizagem desenvolvimentista, promotor ou agente da educação integral dos estudantes, deverão ser globalizadores, sistêmicos, articulados, funcionais e aplicáveis. Danilov e Skatkin (1980) entendem que o conteúdo deve ser estruturado com um enfoque sistêmico, fundamentado em princípios psicopedagógicos, como a sistematização e a lógica da disciplina e do processo didático, para possibilitar a apropriação pelo estudante dos conhecimentos e o desenvolvimento de habilidades que contribuem para o desenvolvimento da atividade criativa e para a formação de atitudes e valores.

Segundo Addine (2004), derivado do enfoque histórico-cultural na perspectiva da Didática Desenvolvimentista, a aprendizagem deve garantir ao estudante a apropriação ativa e criativa da cultura científica, pedagogicamente organizada, propiciando o desenvolvimento integral, o autoaperfeiçoamento constante e a autonomia, em relação aos processos necessários de socialização, compromisso e responsabilidade social. Sendo assim, os conteúdos das ciências naturais objeto de estudo devem atender às referidas finalidades.

O caráter do sistema da organização dos conteúdos implica a não separação dos conhecimentos conceituais das ações nas quais eles se 
aprendem e se aplicam de forma criadora, das habilidades e dos hábitos a serem formados, tudo o que tem como finalidade a formação e desenvolvimento de atitudes e valores.

Sobre a importância que tem o enfoque sistêmico nas ciências, Orudzhev (2000) cita os exemplos do estudo de C. Darwin na sua Teoria da Evolução das Espécies, D. Mendeleiev na elaboração da Lei Periódica dos Elementos Químicos e K. Marx na Teoria Econômico-política do Capitalismo. Em todos os casos, eles chegaram a organizar suas descobertas baseando-as em algum enfoque sistêmico. Darwin desenvolveu um sistema, e não uma classificação formal das espécies biológicas. Mendeleiev organizou os elementos químicos num sistema, como expressão da lei periódica. E Marx definiu a célula da sociedade burguesa, a troca de mercadoria, como a formadora do sistema capitalista, no qual se revelam as contradições dessa sociedade. Nesse sentido, Reshetova (2004) afirma que as ideias da sistematicidade se constituem em um aspecto importante das teorias científicas fundamentais e da concepção contemporânea do mundo. Para a autora, a solução criativa de muitos problemas da atividade científica e profissional depende da capacidade de se pensar de forma sistêmica.

\section{O enfoque sistêmico dialético: aspectos gerais}

Segundo Reshetova, o enfoque sistêmico dialético na organização dos conteúdos de uma disciplina “[...] é um termo usado para denominar as direções metodológicas que aparecem em diferentes ciências concretas unificadas pela tendência de estudar seus objetos como sistema" (RESHETOVA, 1987, p. 32).

De acordo com esse enfoque, o modo de pensar, estudar e abordar os objetos e os fenômenos de uma disciplina não pode ser isolado, mas deve fazer parte do sistema como um todo complexo. Não são as somas de elementos, mas um conjunto de elementos integrados em interações no qual são produzidas novas qualidades superiores em relação aos 
componentes isolados, ou seja, a formação do sistema produz um salto na qualidade do objeto de estudo.

Uma definição de sistema que expressa seu caráter complexo, é dada por V. Afanasiev:

Um conjunto de objetos que em interações produzem uma nova qualidade integradora, não presente nos componentes separados que constituem o sistema. Todo o sistema convencionalmente determinado, se compõe de múltiplos subsistemas, e estes, por sua vez, de tantos outros como permita a sua natureza, que em novas condições, podem ser consideradas como sistemas. Dessa forma, os termos sistema e subsistema são relativos e se usam de acordo com as situações específicas (AFANASIEV,1979, p. 3).

A existência de interações estreitas, do nexo orgânico dos componentes é a base pela qual, na interação com o meio, o sistema sempre aparece como algo único, dotado de determinação qualitativa. $\mathrm{O}$ sistema é uma formação na qual as conexões internas dos componentes entre si prevalecem em relação ao movimento interno desses componentes e sobre a influência extrínseca neles (AFANASIEV, 1979). Para o autor, "o enfoque sistêmico, condicionado pelos requisitos da dialética marxista é, por sua vez, sistêmico, pois têm implícitos vários aspectos, cuja unidade e interconexão são a única que nos proporcionam uma noção profunda e multilateral desse enfoque" (AFANASIEV, 1979, p. 34).

É importante destacar, como afirma Reshetova (2002), que o conjunto e o sistema constituem agrupações diferentes. Na formação de conjunto, o ponto de partida são os elementos, que se combinam para formar um ou outro conjunto. No sistema, pelo contrário, o primário é a integridade, ou seja, o fato de ser um todo composto por partes em interação.

A determinação geral do conceito de sistema reflete as relações dialéticas da integridade do objeto e de sua descrição interna, do caráter 
contraditório de sua natureza e da originalidade qualitativa de todas as suas partes componentes (elementos). É justamente a emergência das novas propriedades a principal peculiaridade da integração e da formação do sistema, segundo Afanasiev (1979).

Para Afanasiev (1979), as propriedades do sistema se caracterizam pelos seguintes aspectos: componentes, estruturais, funcionais e integrativos do sistema. Os componentes do sistema representam a procura pela resposta à pergunta "de que, de quais componentes está formado o todo?”. Eles são as unidades estruturais, cuja interação provoca e garante as peculiaridades qualitativas do sistema.

$\mathrm{O}$ aspecto estrutural diz respeito à forma interna do sistema, que constitui o modo de interconexão e de interação dos componentes que o integram. $\mathrm{O}$ aspecto funcional expressa o fato de todo o sistema ser ativo e manifestar, nas suas funções, o resultado integrado do funcionamento dos componentes que o formam. As funções do sistema podem ser de coordenação e de subordinação. Na primeira, é a concordância das funções dos componentes do sistema na horizontal. A segunda indica o lugar específico particular e a significação desigual de cada componente na realização das funções. Dessa forma, cada sistema dado, na integração das funções de seus componentes, cumpre, ele mesmo, um determinado papel funcional em outro sistema maior e complexo, do qual é parte.

Por último, o aspecto integrativo é essencial no enfoque sistêmico e representa a questão dos fatores de sistematicidade, dos mecanismos que garantem a conservação da especificidade qualitativa do sistema, seu funcionamento e seu desenvolvimento. No sentido filosófico, o fundamento mais geral, universal da sistematicidade é o princípio da concatenação material do mundo, da dialética das interconexões e dos movimentos do sistema.

Na Didática Desenvolvimentista, têm sido usados dois tipos de enfoque sistêmico e dialético para a organização dos conteúdos em diferentes áreas do conhecimento, quais são: o enfoque dialético funcional-estrutural (RESHETOVA, 2002) e o enfoque dialético 
genético (SALMINA, 1988). Neste trabalho, discutimos o enfoque sistêmico dialético genético, que corresponde ao desenvolvido por Salmina (1989), Núnez e González (1996) e Núñez (2009) na organização dos conteúdos do tema "Estrutura das substâncias e dos materiais e suas propriedades físicas" vinculadas à habilidade geral de explicar esse tipo de propriedades na Química.

\section{O enfoque sistêmico dialético genético e o conteúdo "estrutura e propriedades físicas das substâncias e dos materiais"}

A Química é uma ciência que se ocupa de explicar propriedades macroscópicas de substâncias e materiais a partir de sua estrutura. A fim de atingir esse propósito, cria modelos para representar as estruturas das substâncias e relacionar dois níveis: o macroscópico, enquanto fenômenos observáveis, e o microscópico, que representa um dado nível de essência, enquanto modelo teórico (JOHNSTONE, 2006). Dessa forma, a aprendizagem da Química implica o conhecimento de relações dialéticas entre essência e fenômeno.

Como pressuposto da organização dos conteúdos do tema, são definidos um conjunto de ideias estruturantes que permitem sua articulação (HEDESA, 2014). Essas ideias, que devem ser consideradas para organizar o sistema, são: a) as aplicações das substâncias e dos materiais estão relacionadas com suas propriedades e estas, por sua vez, com a estrutura química; b) entre todas as substâncias, orgânicas e inorgânicas, existem relações genéticas; c) as propriedades das substâncias simples e compostas apresentam periodicidade química; d) o desenho de tecnologias que são utilizadas na indústria e no laboratório, a fabricação de outras e de novos materiais para diversos fins estão relacionados às propriedades das substâncias e dos materiais que são usados nesses processos; e) a apropriação dos conhecimentos sobre as propriedades das substâncias e dos materiais possibilita a explicação, assim como poder prever muitos fenômenos, seu comportamento e a 
possibilidade consciente de modificar esse comportamento, criando materiais de maior importância para a ciência, a tecnologia e a sociedade (HEDESA, 2014).

O tema em estudo estrutura-se em três subtemas: estrutura atômica, tabela periódica e ligação química, e estrutura das substâncias e dos materiais, os quais devem ter sentido para os estudantes em relação às possibilidades de responder a perguntas relevantes para a compreensão e a explicação de fenômenos e de processos da natureza. Entre essas perguntas, consideramos: Por que existe uma grande diversidade de materiais e substâncias, em diferentes propriedades, que permitem sua aplicação em diferentes esferas da vida humana? Esse tipo de formulação, que expressa o objeto de estudo da Química, tem sido proposta por autores como Núnez e González (1996), Caamaño (2006), Hedesa (2014), Reshetova (2004) e Salmina e Reshetova (1983). O uso de perguntas como ponto de partida para a organização dos conteúdos é um fator que pode motivar e estimular o pensamento dos estudantes, sua imaginação e curiosidade. (MARTINEZ; GUANCHE, 2009). O pensamento inicia-se quando se deve resolver algum problema, quando se formulam perguntas, face a situações-problema, face ao desconhecido. No mesmo sentido, Ilienkov (1977) afirma que é necessário ensinar a pensar, em especial, pelo desenvolvimento da capacidade de formular perguntas.

De acordo com lógica dialética, se um objetivo das ciências é conhecer a essência do objeto, faz-se necessário conhecer seu processo de desenvolvimento e suas relações com os outros objetos (DAVIDOV, 1988). Esse é um argumento a favor do enfoque genético dialético para a organização dos conteúdos em uma disciplina como a Química. Nesse enfoque, descreve-se o objeto complexo (as substâncias e os materiais) como resultado do desenvolvimento dialético de um elemento inicial do sistema (a célula geradora do sistema). O objeto complexo é considerado geneticamente desde o ponto de vista da origem das propriedades integrais do sistema. As relações genéticas constituem o tipo principal de 
relações de desenvolvimento. O conceito inicial gerador do sistema (a célula ou conceito-célula) e as contradições presentes nesse conceito definem a tendência de seu desenvolvimento no todo (SALMINA, 1988).

Dessa forma, a base geral de partida do sistema teórico, o conceitocélula, expressa as determinações teóricas concretas de um fenômeno típico, particular, que se manifesta na prática. Salmina (1989) destaca que a estruturação do conteúdo, a partir do enfoque genético, pressupõe: a) a análise empírica do estado de desenvolvimento do objeto; b) a distinção da estrutura geneticamente inicial mais simples, ou seja, o conceito-célula gerador do sistema; c) a distinção das leis de desenvolvimento do simples ao complexo como sistema, que revelam as contradições inerentes ao objeto de estudo.

A célula geradora do sistema é um conceito simples, de caráter universal, que expressa uma contradição essencial, de forma tal a permitir que, uma vez desenvolvido, estruture o sistema e, consequentemente seu conteúdo. A célula geradora do sistema pode ser considerada como uma estrutura estável, contraditória e em movimento presente em todo o sistema. Para Ilienkov (1977), a contradição como unidade concreta de contrários que se excluem mutuamente é o núcleo da dialética, sua categoria central. A luta entre as tendências opostas e implícitas nos objetos e fenômenos constitui a fonte ou força-motriz de seu desenvolvimento.

As contradições atuam como forças motoras do desenvolvimento, que fazem avançar e condicionam a passagem de um estágio de desenvolvimento inferior para um superior. Os contrários são aspectos cujos sentidos de transformação são opostos e cuja interação constitui a contradição ou "luta" de contrários. A unidade de contrários é seu estabelecimento recíproco, ou seja, os aspectos ou as tendências contrárias não podem existir um sem o outro. Dessa forma, como explica Cheptulin (2004), a contradição pode ser considerada como a unidade dos contrários que se excluem e incluem mutuamente. Kopnin (1996) destaca que as contradições podem serem internas ou externas. As 
primeiras são as que se produzem, surgem ou aparecem como consequência das interações de contrários no nível da essência mesma do objeto ou fenômeno onde ocorrem. As segundas ocorrem nas interações entre o objeto ou fenômeno com os outros externos com os quais coexistem.

Ilienkov (1977) pondera que ensinar a pensar significa ensinar a pensar de forma dialética, o que implica a habilidade de ver as contradições e encontrar sua solução no campo concreto da realidade, e não só usando manipulações verbais formais que a mascaram.

Por sua vez, ao expressar sua posição, Salmina (1989, p. 24) argumenta:

O procedimento de estruturação da disciplina através da distinção das relações formadoras do sistema de caráter genético, pressupõe a determinação de uma estrutura geneticamente inicial simples (denominada célula do objeto de estudo) e das leis de desenvolvimento desta estrutura no sistema complexo. O conceito "célula" do todo e a contradição contida nela, determina a tendência fundamental de seu completo desenvolvimento no todo.

Entre as características da célula, Salmina (1989) destaca que: a) é a relação mais simples (elementar) do todo desenvolvido; b) é a relação geral universal, própria ao objeto em todas as etapas de seu desenvolvimento e que reflete em si a lei da existência do sistema; c) é a relação que reflete a contradição principal - a fonte de movimento e o desenvolvimento no todo; d) é a relação que inclui a possibilidade de desenvolvimento do sistema; e) é a relação que tem caráter relativo e dependente do sistema, possui um protótipo real direto e se manifesta para o sujeito conhecer e atuar como a base organizadora do movimento e o ponto de partida da investigação.

O conceito-célula representa um nível de essência do sistema complexo. A essência é o aspecto interno, relativamente estável, da realidade objetiva, que determina a natureza do fenômeno. Este, por sua 
vez, é o aspecto externo, mais dinâmico da realidade objetiva, na qual se revela a essência. Como justifica Kopnin (1966), não há essência pura que não se manifeste no fenômeno.

A essência (a célula geradora do sistema) e o fenômeno (as substâncias, os materiais e suas propriedades físicas) formam uma unidade dialética, estão unidos, mas em oposição, não coincidem entre si, sendo resultado de contradições internas das partes que se relacionam no objeto, considerando o princípio da causalidade.

Uma das formas que representa a correlação sujeita a leis dos fenômenos é a causalidade. Como argumenta Kopnin (1966), as ciências se esforçam por descobrir, no estudo dos fenômenos, as causas de sua origem, de seu desenvolvimento e de sua transformação. Dessa forma, a causalidade expressa o nexo entre dois fenômenos, em virtude da qual um produz o outro. Por meio dessa relação, refletem-se no pensamento regularidades, nexos importantes entre os fenômenos. Essa relação não pode ser vista como uma determinação fechada, mas como relações mútuas e nexos entre fenômenos.

Para Núñez (2009), a seleção da célula é um processo complexo que exige do professor um profundo conhecimento do objeto de estudo no nível teórico e dos métodos especiais de análise desse objeto complexo. A determinação da célula de um tema em uma disciplina, para o professor, constitui um processo de estudo e de pesquisa teórica, considerando a complexidade do processo de identificação de uma relação elementar que, por sua natureza contraditória, possibilita compreender o desenvolvimento do sistema. Para o estudante, constitui um momento de orientação, de elaboração de uma metodologia de análise do objeto de estudo que permite pensar e resolver diferentes problemas sob uma perspectiva complexa e sistêmica.

Na compreensão de Reshetova (2004), o estudo dos fenômenos, no seu desenvolvimento, constitui um princípio básico da pesquisa científica que também aponta para a necessidade de se estudarem as particularidades do processo como casos concretos, expressão de uma 
essência, na dialética do geral e do singular, o que se justifica no propósito de compreender, diagnosticar e prever comportamentos e poder agir para a sua transformação.

$\mathrm{O}$ aspecto interno das substâncias e dos materiais e suas propriedades se expressa pelos conhecimentos teóricos construídos pela Química como ciência. É um processo que articula o externo ou fenomenológico (as substâncias, os materiais e suas propriedades) com o interno ou a essência (a estrutura). A compreensão do aspecto interno serve de base teórica para uma prática social mais consciente, reflexiva e crítica, o que contribui para o desenvolvimento do pensamento teórico e possibilita não só explicar, argumentar ou prever o comportamento das substâncias e dos materiais, mas também transformá-los e obter novos materiais necessários ao desenvolvimento da ciência, da tecnologia e da sociedade em geral.

\section{Organização didática das atividades de ensino como base ao enfoque sistêmico dialético genético do conteúdo}

\subsection{Determinação do conceito-célula e formação do sistema}

O estudo do conteúdo "Estrutura das substancias e dos materiais e suas propriedades físicas" pode ser iniciado com uma problematização, ou seja, usando situações-problema que justifiquem a importância e a necessidade de se estudarem as relações entre estrutura e propriedades das substâncias e dos materiais, assim como serve de motivação para a atividade de construção de um modelo geral que explique propriedades e se relacione com as aplicações. O estudo do tema inicia-se pelo final, isto é, por onde se que chegar; nesse caso, a elaboração de uma orientação adequada para a formação e o desenvolvimento da habilidade de explicar propriedades físicas das substâncias e dos materiais, e viceversa, desenhar estruturas que respondam a determinadas propriedades, como hipótese, de forma dialética, o que ajuda a justificar o estudo do 
tema, articulando e dando sentido aos conteúdos da estrutura atômica, da tabela periódica e da ligação química.

Assume-se como conceito-célula "o elétron no átomo", como unidade dialética mais simples, desde o ponto de vista da característica da mudança dos estados dos orbitais do átomo, definido por Salmina (1989), Núñez (2009) como o conceito gerador do sistema. Salmina (1989) justifica a necessidade de distinguir o átomo do elétron no átomo como formador do sistema químico. Segundo essa autora, a maior parte das reações entre materiais pode ser interpretada em termos de mudanças nas configurações eletrônicas que rodeiam o núcleo atômico. O sistema do conteúdo em estudo pode ser representado conforme esquema da Figura 1.

Figura 1 - Representação do sistema gerado pelo conceito célula

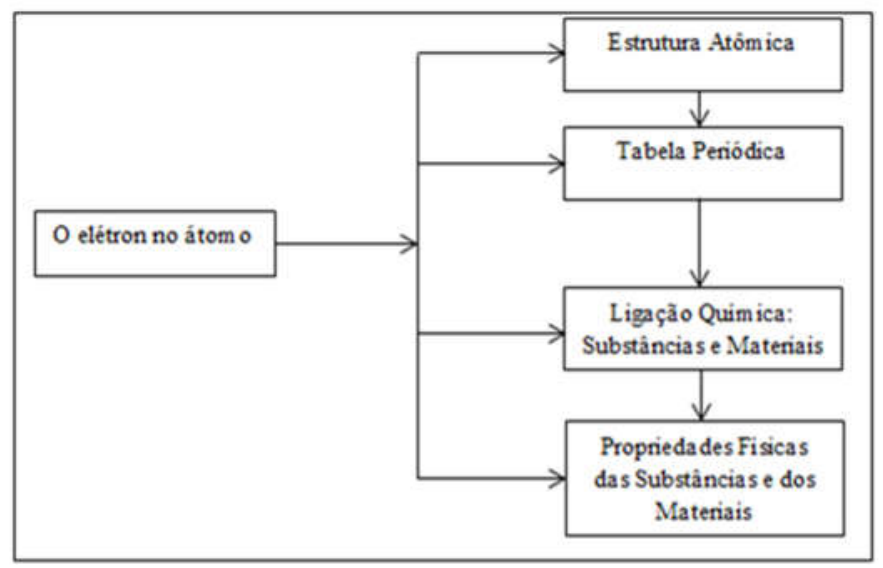

Fonte: Elaborado pelos autores.

As contradições essenciais (internas) que se geram nas estruturas das substâncias são promotoras de novos níveis estruturais no sistema, o que, de acordo com a dialética, representa diferentes níveis de desenvolvimento na forma de uma espiral dialética. 
O desenvolvimento do sistema, ou seja, de novas substâncias e novos materiais, partindo da célula geradora, produz-se na forma de uma espiral dialética. Como explica Kopnin (1966), a realidade dialética é um processo dinâmico de superação, de interação e "luta" interna de seus elementos contrários; mas, depois, continua um novo ciclo dessa luta de contrários em um novo movimento qualitativamente superior, que sintetiza as contradições anteriores.

Os estudantes podem deduzir o desenvolvimento do simples ao complexo com base no modelo eletrostático do átomo, segundo duas leis gerais. Por lei, na dialética, compartilhamos as ideias de Cheptulin (2004), quando considera a lei como uma determinada relação necessária entre fenômenos ou processos, relação que responde à natureza interna, à essência deles. Dessa forma, a lei é uma fase do conhecimento da unidade, dos nexos e a ação mútua dos fenômenos da realidade objetiva, resultado de um longo e complexo processo das ciências. A lei é a relação necessária entre os fenômenos em determinadas condições. Nesse sentido, as leis que podem ajudar na elaboração teórica do sistema, segundo a célula geradora, são:

a) Lei 1: um aumento de carga do núcleo (adição de um próton) implica um aumento do número de elétrons em sua volta, até que se iguale ao número atômico (átomo estável). No átomo estável, existem forças de atração do núcleo até os elétrons e de repulsão, pois cada elétron não só é atraído pelo núcleo como também é repelido por outros elétrons. A energia de cada elétron depende, em essência, dessas contradições e pode ser quantificada pela carga nuclear efetiva (Zef). Segundo essa ideia, pode-se criar um modelo no qual o desenvolvimento de um átomo mais simples a outro mais complexo produz-se pela adição de uma carga positiva (próton) ao núcleo e de um elétron em sua volta, segundo o princípio de construção. Assim, as características energéticas do novo elétron são dadas pelo valor dos números quânticos e pela contradição principal mencionada. 
b) Lei 2: o desenvolvimento que implica um átomo se combinar com outro está relacionado às contradições internas e é determinado, em última instância, pelo estado energético dos elétrons de valência dos átomos, que podem "transferir-se" ou serem "compartilhados", diminuindo a energia do agregado atômico formado. A partir dessas ideias, pode-se construir um modelo sobre a ligação química nesse nível (NÚNEZ; GONZÁLEZ, 1996).

A estrutura atômica, as propriedades atômicas periódicas e as ligações químicas são subtemas que se desenvolvem e integram por meio da célula geradora do sistema como um fio condutor, "o elétron no átomo", como uma espiral dialética. Os estudantes podem construir, seguindo esse fio condutor, a lei periódica, o comportamento periódico das propriedades, as substâncias, as ligações químicas e as estruturas das substâncias e dos materiais.

Depois que os estudantes adquirem os primeiros esquemas mentais ou representações mentais, podem compreender e construir outros conteúdos compatíveis rapidamente, assim como proporcionar a discussão de outros modelos sobre a estrutura dos átomos e das ligações químicas. Essa correlação de modelos é necessária à compreensão da própria natureza da Química como ciência. É importante, na aprendizagem dos modelos teóricos, que os estudantes tenham consciência dos seus limites de aplicação bem como da natureza desses modelos para poder aplicá-los em outros contextos e outras situações adequadas.

A atividade dedutiva-investigativa pode ter a seguinte ordem: a) conceito formador do sistema (o elétron no átomo); b) orbital atômico (esse conceito se deduz a partir das teorias modernas da mecânica quântica); c) representação do sistema formado a partir desse conceito; d) estruturas eletrônicas dos átomos (deduz-se levando em conta os princípios e as regras gerais sobre os elétrons nos níveis eletrônicos); e) classificação dos elementos químicos segundo a estrutura eletrônica (deduzem-se as estruturas eletrônicas dos átomos e a natureza dos elementos químicos) 
e f) lei periódica (deduz-se a partir das configurações dos átomos dos elementos, descobrindo a regularidade na configuração eletrônica) (NÚNEZ; GONZÁLEZ, 1996).

É importante destacar a Lei Periódica como expressão de regularidades e a tabela periódica como representação da lei. O termo periodicidade indica repetição de propriedades em intervalos determinados. A repetição periódica das propriedades físicas e químicas das substâncias simples ou compostas se expressa mediante uma lei a qual estabelece que elas variam periodicamente com o aumento do número atômico dos elementos químicos, como mudanças quantitativas em qualitativas e vice-versa, como negação da negação e como interação e luta dos contrários (CHEPTULIN, 2004).

Essa ideia estruturante orienta o estudo da Lei Periódica e sua representação gráfica, a Tabela Periódica. A periodicidade, nas propriedades dos elementos, das substâncias simples e compostas, deve ser mostrada a partir: a) dos átomos dos elementos químicos - estruturas eletrônicas, fundamentalmente, nos níveis mais externos; b) das substâncias simples dos elementos químicos - redes cristalinas com o tipo de ligação química que une os átomos (substâncias atômicas com ligação metálica, atômicas com ligação covalente e moleculares) e propriedades oxidantes e redutoras e c) das substâncias compostas, óxidos e hidróxidos dos elementos químicos - variação do maior número de oxidação dos elementos ligados ao oxigênio e ao hidróxido, variação das redes cristalinas e das propriedades ácido-base.

As propriedades atômicas periódicas são deduzidas a partir de investigações sobre como varia a carga nuclear efetiva e da força com que o núcleo atrai os últimos elétrons no átomo. A ligação química deduz-se a partir do elétron no átomo e dos átomos dos elementos que interagem. Investigam-se as condições de formação da ligação química sobre a base das estruturas eletrônicas dos átomos e dos princípios dos elétrons nos níveis eletrônicos nos átomos e, a partir desse conhecimento, as substâncias e os materiais. É importante que os estudantes 
compreendam que as diferenças qualitativas e quantitativas entre diversas interações podem explicar propriedades observáveis das substâncias e dos materiais.

Faz-se necessário distinguir o conceito de substância dos conceitos de materiais e de matéria. Assim, a substância é definida como o constituinte de certo material que apresenta propriedades específicas que a diferenciam das outras substâncias (RAVIOLO; GARRITZ; SOSA, 2011). O material é definido como uma porção da matéria que contém mais de uma substância. A substância se relaciona com um material que tem um grau de pureza adequado aos parâmetros exigidos. Dessa forma, por não existir 100\% de pureza, substância é uma abstração de grande importância para a Química.

As substâncias e os materiais e suas propriedades explicam-se, e deduzem-se as propriedades macroscópicas de algumas substâncias de interesse a partir de investigação do tipo de ligação entre os átomos, a estrutura da substância, o tipo de partículas e a intensidade da interação entre partículas constituintes das substâncias em uma relação dialética entre a essência e o fenômeno.

\subsection{A organização do processo de explicar propriedades de substâncias e materiais}

Uma vez que uma das finalidades do estudo desses conteúdos é que os estudantes expliquem as propriedades físicas de substâncias e materiais relacionados com as estruturas, o que, por sua vez, se relaciona com suas aplicações, na próxima etapa, constrói-se com os estudantes uma orientação geral para explicar propriedades das substâncias e dos materiais, que, como diz Núñez (2009), pressupõe a construção de uma invariante operacional-conceitual da ação. Esse modelo que atua como orientação geral deve responder a uma situação-problema, típica de um processo que possibilite uma generalização teórica. 
A situação-problema pode, hipoteticamente, ser formulada, conforme mostrado no Quadro 1, como um caso particular, da situação mais geral apresentada no início do tema, ressaltando que cada situação deve considerar os conhecimentos prévios e os níveis de desenvolvimento inicial da habilidade de explicar dos estudantes ou que deve integrar a caracterização do desenvolvimento real (ADDINE, 2004).

\section{Quadro 1 - Formulação da situação-problema}

Explicar por que o $\mathrm{NaCl}$ é um sólido cristalino nas condições ambientes e, nessas mesmas condições, o $\mathrm{CCl}_{4}$ não é solúvel em água e o $\mathrm{Fe}$ sólido conduz corrente elétrica. O que é explicar propriedades físicas das substâncias e dos materiais? É possível encontrar um procedimento comum que possibilite explicar as propriedades dessas substâncias? Quais passos podem ser seguidos para essa finalidade?

Fonte: Elaborada pelos pesquisadores.

No processo de construção do sistema com base na célula geradora, não só se deve garantir a elaboração conceitual necessária como também é essencial que os estudantes se apropriem das ações necessárias para a aprendizagem dos conceitos e para sua aplicação na solução de diferentes tarefas que potencializam o seu desenvolvimento integral. Essas ações, quando passam ao domínio dos estudantes, constituem-se em operações necessárias à habilidade geral do tema: explicar propriedades físicas das substâncias e dos materiais, considerando a estrutura.

Isso significa uma sistematicidade e uma integração das ações nos diferentes subtemas do tema em estudo. Essas ações devem ser do domínio dos estudantes enquanto operações que se integram à habilidade geral. Durante seu estudo, o estudante compreende e dá sentido a tais ações, na medida em que vai tomando consciência do sistema como um todo.

O professor deve dispor de um modelo de orientação invariante que, como orientação, possibilite responder à situação-problema, 
considerando os limites dos modelos teóricos. A partir dessa orientação (como significado), desenvolve uma discussão com as propostas dos estudantes (sentidos diversos) para, de forma negociada, chegar a um modelo da atividade que reflita o sistema geral de ações e operações da habilidade "explicar propriedades físicas das substâncias e dos materiais". Nas pesquisas realizadas por Núnez e Ramalho (2017), temse usado, como modelo de orientação da atividade de explicar, propriedades físicas observáveis de substâncias conforme apresentado no Quadro 2.

Quadro 2 - Modelo de orientação da atividade de explicar propriedades físicas de substâncias

\begin{tabular}{|c|c|}
\hline Modelo do objeto "explicar propriedade" & Modelo da ação. Sistema de operações \\
\hline $\begin{array}{l}\text { Explicar propriedades das substâncias e dos } \\
\text { materiais significa correlacionar as } \\
\text { propriedades macroscópicas (fenômeno) } \\
\text { com os modelos teóricos (essência) nos } \\
\text { quais se podem encontrar argumentos para } \\
\text { justificar as causas desses comportamentos } \\
\text { das substâncias e dos materiais nas } \\
\text { condições dadas. Significa relacionar os } \\
\text { níveis macroscópicos e microscópicos. }\end{array}$ & $\begin{array}{l}\text { - Determinar composição da substância ou } \\
\text { do material a partir de fórmulas; } \\
\text { - Determinar a natureza dos átomos que } \\
\text { entram na composição da substância; } \\
\text { - Determinar o tipo de ligação entre os } \\
\text { átomos segundo a natureza dos átomos ou } \\
\text { segundo a diferença de } \\
\text { eletronegatividade; } \\
\text { - Determinar o tipo de partículas presentes } \\
\text { e a estrutura da substância; } \\
\text { - Caracterizar o tipo de interação entre as } \\
\text { partículas assim como a intensidade } \\
\text { relativa das interações; } \\
\text { - Correlacionar a propriedade com o } \\
\text { modelo teórico e dar razões do porquê } \\
\text { desse comportamento da substância nas } \\
\text { condições dadas; } \\
\text { - Correlacionar as propriedades com as } \\
\text { aplicações. }\end{array}$ \\
\hline
\end{tabular}

Fonte: Núnez e Ramalho (2017). 
Para estimular a elaboração de um modelo ou uma representação da ação explicar propriedades físicas das substâncias e dos materiais, o professor pode motivar os estudantes a formular perguntas, negociar significados e sentidos entre eles e o professor, na busca de respostas à situação-problema e às perguntas formuladas.

Núnez e Ramalho (2017) consideram que essa representação inclui: a) os objetivos e o produto da atividade; b) a estrutura das operações da ação e a sua definição conceitual; c) os critérios para o controle e a regulação da ação; d) os recursos necessários e disponíveis para a realização da ação e e) as condições nas quais será realizada a ação. Como se observa, a representação da ação de controle está incluída na representação da base orientadora de ação, pois o controle é inseparável da orientação e da execução.

Entre essas perguntas, podemos considerar: Por que se deve realizar a ação? O que me motiva? O que desejo? O que se quer como resultado? Quais operações devem ser realizadas e em qual ordem? Quais condições são necessárias e quais existem? De quais recursos preciso e de quais disponho? Como acompanhar e corrigir a realização da atividade? Nessa teoria, considera-se que a formulação de perguntas para o pensamento é de grande importância.

O conteúdo conceitual não pode apenas representar o contexto de aplicação das teorias, do fazer da escola que separa os procedimentos de seu uso, como criticam Davidov e Slobodchikov (1991, p. 54). De acordo com a lógica dialética, segundo os autores,

A realidade do conhecimento não está fechada nas abstrações verbais, mas sim nos procedimentos da atividade do sujeito cognoscente para quem a transformação dos objetos, a fixação dos meios para realizar essas transformações constitui componentes tão indispensáveis do 'conhecimento' como sua expressão verbal. 
Essa ideia pode ser fundamentada com base no alerta de Marx (1968), para quem ao conhecimento do objeto de estudo pertence não só o resultado como também o caminho, o qual se institui, por sua vez, como um conhecimento do referido objeto.

No modelo de orientação da ação, estão explicitados o conteúdo conceitual da ação e o modelo da ação ou sistema operacional, como uma hipótese de orientação a ser negociada com os estudantes. Como explica Talizina (2001), a ação e o conceito formam uma unidade indissociável.

Na opinião de Rubtosov (1996), a assimilação de um método teórico geral que visa à resolução de uma série de problemas concretos e práticos, concentrando-se naquilo que eles têm em comum e não na resolução específica de um entre eles, constitui-se em uma característica essencial da aprendizagem. Para o autor, o método teórico generalista possibilita a solução de todas as variantes concretas nas quais se pode aplicar esse método.

Esse tipo de atividade permite que o estudante possa realizar um prognóstico acerca da possibilidade de existência de substâncias e de materiais com determinadas estruturas e descrever suas propriedades físicas concretas ao dispor de um método geral de análise. É um método de análise que, por seu caráter geral, facilita a transferência da aprendizagem a novas situações, potencializando a criatividade (NÚÑEZ, 2009). Desse modo, esse tipo de ensino permite aos estudantes resolver situações que não lhe foram ensinadas, mas que estão dentro dos limites de aplicação da orientação construída, o que é típico do pensamento teórico.

Segundo Talizina (2001), a orientação baseada no enfoque sistêmico libera o homem da necessidade de estudar cada fenômeno particular da área de conhecimento dada. Essa orientação sistêmica constitui um novo modo de armazenamento de informação, ou seja, não se estuda uma grande quantidade de fatos particulares por métodos particulares, mas um método de análise com o qual se abordam alguns casos típicos do conjunto, necessários para a assimilação do método, para 
possibilitar ao estudante compreender, de forma independente, qualquer fenômeno do sistema dado.

\section{Contribuições do enfoque sistêmico dialético genético para o pensamento teórico}

O foco da atenção, ao estruturar os conteúdos das disciplinas, deve estar na aprendizagem a ser modelada e nos métodos de transformação e de construção da realidade pelos estudantes. Nesse sentido, Talizina (2001) chama a atenção para o fato do estudante poder desconhecer certas regras e recomendações particulares; porém, o importante é que eles assimilem os métodos gerais a partir dos quais poderão dar solução às tarefas que contribuam para o desenvolvimento integral, o que significa a formação de um pensamento do tipo teórico.

Como características do pensamento teórico construído a partir da organização sistêmica dialética dos conteúdos proposta neste trabalho destacam-se: a) os conhecimentos teóricos surgem no processo de análise do papel e da função de certa relação peculiar no sistema integral, que, por sua vez, serve de base genética inicial de todas as suas manifestações; b) o processo de análise permite descobrir a relação geneticamente inicial do sistema integral como sua base inicial ou essência; c) ao ter sua origem na base das transformações mentais dos objetos, o pensamento teórico reflete suas relações e conexões internas, pelo fato de saírem dos limites das representações; d) o pensamento teórico fixa o enlace da relação universal, realmente existente, do sistema integral com suas diferentes manifestações, ele expressa o enlace do universal com o singular e e) o pensamento teórico concretiza-se na dedução e na explicação das manifestações particulares e singulares do sistema integral em seu fundamento universal.

Para Davidov e Slobodchikov (1991), o pensamento teórico "supera", assimila os momentos positivos do pensamento empírico, como sua negação dialética. Dessa forma, o pensamento empírico não 
perde sua importância na aprendizagem de determinado conteúdo na escola, mas o ensino que desenvolve está orientado ao desenvolvimento do pensamento teórico, que se encontra na base da atividade criativa, como expressão da cientificidade da educação escolar.

Davidov e Slobodchikov (1991) entendem que a organização dos conteúdos escolares que favorece a formação do pensamento teórico dos estudantes deve considerar que: a) os estudantes assimilem os conceitos da disciplina sobre a base da análise das condições de sua origem (os conceitos não se apresentam prontos); b) a assimilação dos conhecimentos de caráter geral e abstrato precede a aprendizagem de conhecimentos mais particulares e concretos, os segundos devem ser deduzidos do abstrato não desenvolvido, de sua origem, segundo a exigência do acesso do abstrato ao concreto; c) no estudo das fontes objetais-materiais de um ou outros conceitos, os estudantes devem encontrar a conexão genética inicial, universal, que determina o conteúdo e a estrutura de todo o sistema de conceitos; d) é indispensável reproduzir essa conexão em modelos especiais objetais, de modo tal a permitir estudar as propriedades das conexões na "forma pura"; e) é importante formar nos estudantes as ações objetais por meio das quais eles podem aprender e usar nos modelos a conexão essencial do objeto e estudar suas propriedades e f) na aprendizagem, os estudantes devem passar sucessivamente de ações com objeto ou suas representações para seus substitutos semânticos e a sua realização no plano mental.

É certo que a proposta de organização dos conteúdos tem seus limites de aplicação, na medida em que os aspectos teóricos (os modelos e as teorias que entram nesse conteúdo) têm seus limites de aplicação, o que deve ser explicitado e trabalhado. Os estudantes devem aprender de forma consciente a determinar as possibilidades de aplicação ou não dessa metodologia de análise do objeto de estudo da Química, nesse caso, as substâncias, os materiais e suas propriedades físicas (NÚNEZ; RAMALHO, 2017). 
No processo de apropriação dos conteúdos das substâncias, dos materiais e suas propriedades, é importante que os estudantes não vejam a Química como uma ciência imutável, caracterizada por leis naturais estáticas, algo típico do positivismo. Uma análise das teorias que os químicos foram elaborando ao longo dos anos deve mostrar como o conhecimento sobre a estrutura das substâncias vai, cada vez mais, penetrando a essência das próprias substâncias e dos materiais, inventando um mundo submicroscópico, em que leis naturais conhecidas até então tiveram de ser revisadas. Dessa forma, os estudantes constatarão, na história da Química, que essa disciplina não é dogmática ou uma sequência linear de ideias, senão que a maioria dos avanços é consequência de intensas discussões que provocam rupturas dialéticas entre o velho e o novo. Isso ajudará os estudantes a compreenderem que cada explicação teórica tem validez para um contexto determinado, no qual o problema foi proposto, referindo-se cada teoria aos conhecimentos experimentais disponíveis de uma época determinada.

\section{Conclusões}

Com a estruturação sistêmica dialética do conteúdo, compreender um fenômeno significa esclarecer seu lugar e seu rol no interior do sistema concreto de fenômenos em interação, o que permite dar sentido às particularidades graças as quais esse fenômeno desempenha esse rol no todo. Compreender um fenômeno significa esclarecer seu modo de aparição e as regras segundo as quais essa aparição cumpre com uma necessidade contida num conjunto concreto de condições, o que significa analisar as condições de aparição e desenvolvimento dos fenômenos como sistemas complexos. Dessa forma, o estudante pode apropriar-se, de forma consciente, dos conteúdos, o que inclui um método sistêmico dialético de análises do objeto de estudo, de forma a contribuir para o desenvolvimento de seu pensamento dialético e sistêmico. 
A aplicação do enfoque sistêmico dialético na organização dos conteúdos permite aos estudantes elaborar uma representação integral do objeto do conhecimento, de seus componentes e vínculos, níveis, tipos e transformações em função das interações que se estabelecem entre eles e com o meio. Permite também se apropriar de uma orientação sistêmica no objeto de estudo assim como potencializar o desenvolvimento da criatividade, uma vez que se trata da aplicação de procedimentos heurísticos.

A estruturação sistêmica dialética dos conteúdos, como têm mostrado as pesquisas de Núñez (2009), contribui para tornar os conhecimentos mais significativos na medida em que se relacionam ou estão relacionados com outros conhecimentos já assimilados e compreendidos. Para os estudantes, é mais fácil aprender conteúdos que tenham relação significativa do que conteúdos num contexto de uma relação mais ou menos arbitrária. $\mathrm{O}$ processo de aprendizagem baseado nesse enfoque possibilita o desenvolvimento do pensamento criativo, uma vez que os estudantes, com ajuda de um método de análise do objeto de estudo, participam da construção e do desenvolvimento desse método.

O enfoque sistêmico dialético no programa de Química Geral propõe uma dada lógica de integração disciplinar. É óbvio que esse não é o único caminho. A organização sistêmica dialética dos conteúdos da Química proposta é um esquema geral que pode se constituir em uma referência no contexto da Didática Desenvolvimentista, e não numa única via.

No enfoque genético, que toma como eixo a contradição dialética no objeto de estudo, pode-se realizar a análise causal de propriedades físicas das substâncias e dos materiais dentro dos limites da aplicação dos modelos teóricos que explicam essas propriedades, o que confere potencial aos pensamentos dialético e teórico. Face as considerações discutidas neste trabalho, recomendamos que esse conhecimento possa ser agregado à base de conhecimentos da atividade profissional do ensino de Química, na formação inicial e continuada dos professores. O enfoque 
sistêmico dialético genético, como arquitetura teórica do objeto de estudo da Química, fornece ao estudante uma forma dialética de pensar, um esquema de pensamento (lógico-dialético) com o qual se pode pensar sobre as substâncias e os materiais, suas propriedades físicas, produção e aplicações. Além disso, permite que o estudante assimile a lógica da análise sistêmica e a converta em lógica de seu próprio pensamento.

\section{Referências}

ADDINE, F. A. Didáctica. ¿E que didáctica? In: ADDINE, F. A. Didáctica, Teoría y Práctica. La Habana: Editorial Pueblo y Educación, 2004. p. 12-29.

AFANASIEV, V. El enfoque sistémico aplicado al conocimiento social. Revista Ciencias Sociales Contemporáneas, Academia de Ciencias. URSS, CEIS, Bogotá, n. 11, p. 32-45, 1979.

CAAMAÑO, A. Retos del curriculum de Química en la educación secundaria. La selección y contextualización de los contenidos de Química en los curriculum de Inglaterra, Portugal, Franca e España. Educación Química, Ciudad de México, v. 17(X), p. 195-208, 2006. https://doi.org/10.22201/fq.18708404e.2006.4e.66008

CHEPTUlin, A. A Dialética Materialista. Categorias e Leis da Dialética. São Paulo: Alfa-Ômega, 2004.

DANILOV, M. A.; SKATKIN, M. N. Didáctica de la escuela media. La Habana: Libro para la Educación, 1980.

DAVIDOV, V, V. La enseñanza escolar y el desarrollo psíquico, investigación psicológica teórica y experimental. Moscú: Progreso, 1986.

DAVIDOV, V, V. El contenido y la estructura de la actividad docente de los escolares. La Habana: Editorial Pueblo y Educación, 1988.

DAVIDOV, V. V.; SLOBODCHIKOV, V. I. La enseñanza que desarrolla en la escuela del desarrollo. In: MUDRIK, A. B. (Org.). La educación y la enseñanza: una mirada al futuro. Moscú: Editorial Progreso, 1991. p. 34-58. 
GALAGOVSKY, L. R. La enseñanza de la química pré-universitaria: ¿O qué enseñar, cómo, cuánto, para quienes? Revista Química Viva, Buenos Aires, año 4, n. 1, p. 8-22, Mayo, 2005.

GALPERIN, P. YA. Tipos de orientación y tipos de formación de acciones y de los conceptos. In: ROJAS, L. Q. (Comp.). La formación de las funciones psicológicas durante el desarrollo del niño. Tlaxcala: Editora Universidad Autónoma de Tlaxcala, 2001. p. 41-56.

HEDESA, J. P. Didáctica de la Química. La Habana: Editorial. Pueblo y Educación, 2014.

ILIENKOV, E. V. Lógica Dialéctica. Moscú: Editorial Progreso, 1977.

IZQUIERDO, M. A. Hacia una teoría de los contenidos escolares. Enseñanza de las Ciencias, Vigo, v. 23, n. 1, p. 111-122, 2005.

JOHNSTONE, A. H. Chemical Education Research in Glasgow in Perspective. Chemical Education Research and Practice, Cambridge, v. 7, n. 2, p. 262-268, 2006. https://doi.org/10.1039/B5RP90021B

KOPNIN, P. V. Lógica Dialéctica. Ciudad de México, DF: Editorial Grijalbo, 1966.

MARTINEZ, M. LL.; GUANCHE, A. M. El desarrollo de la creatividad. Teoria y práctica en la educación. La Habana: Editorial Pueblo y Educación, 2009.

MARX, C. Obras escogidas de Marx y Engels. Tomo 2. Berlín: Verlag, 1968.

NÚÑEZ, I. B. Vygotsky, Leontiev, Galperin. Formação de conceitos e princípios didáticos. Brasilia. Liber Livro, 2009.

NÚÑEZ, I. B.; GONZÁLEZ, O. P. La estrucutración de los contenidos de la disciplina Química General. Uma nueva propuesta. Química Nova, São Paulo, v. 19, n. 5, p. 558-562, 1996.

NÚÑEZ, I. B; RAMALHO, B. L. A teoria da Formação Planejada das Ações Mentais e dos Conceitos de P. Ya. Galperin: contribuições para a Didática Desenvolvimental. Obutchénie, Uberlândia, v. 1, n. 1, p. 1-29, jan/jul. 2017. https://doi.org/10.14393/OBv1n1a2017-4 
ORUDZHEV, Z. M. La dialéctica como sistema. Monterrey: Ediciones de la Facultad de Filosofía y Letras/UANL, 2000.

POZO, J. I.; GÓMEZ CRESPO, M. A. A aprendizagem e o ensino de ciências. Do conhecimento cotidiano ao conhecimento científico. Porto Alegre: Artmed, 2009.

RAVIOLO, A.; GARRITZ, A.; SOSA, P. Sustancia y reacción como conceptos centrales en química. Una discusión conceptual, histórica y didáctica. Revista Eureka sobre enseñanza y divulgación de las Ciencias, Puerto Real, v. 8, n. 3, p. 240-254, 2011. https://doi.org/10.25267/Rev_Eureka_ensen_divulg_cienc.2011.v8.i3.02

RESHETOVA Z. A. Realización de los principios del enfoque sistémico en las asignaturas. La Habana: CEPES, 1987.

RESHETOVA Z. A. Organization of mastering activity and development of the pupil. Questions of psychology, Abingdon, n. 5, p. 71-78, 2002.

RESHETOVA Z. A. The organization of the activity of learning and the student's development. Russian Education and Society, Abingdon, v. 46, n. 9, p. 46-62, 2004. https://doi.org/10.1080/10609393.2004.11056909

RUBTOSOV, V. A atividade de aprendizagem e os problemas referentes à formação do pensamento teórico dos escolares. In: GARNIER, C.; BEDNARZ, N.; ULANVSKAYA, I. Após Vygotsky e Piaget: perspectiva social e construtivista: a escola russa e ocidental. Porto Alegre: Artes Médicas, 1996. p. 129-137.

SALMINA, N. G. Análisis lógico-psicológico de los procedimientos para discutir la asignatura docente. Educación Superior Contemporánea, La Habana, v. 3, n. 47, p. 35-46. 1988.

SALMINA, N. G. La Actividad Cognoscitiva de los alumnos y el método de estructurar la asignatura. La Habana: CEPES, 1989.

SALMINA, N. G.; RESHETOVA, Z. A. Enfoque sistémico estructural en la asignatura de Química. Moscú: Editado por la Universidad de Moscú, 1983. 
TALIZINA, N. F. La formación de las habilidades del pensamiento matemático. San Luis Potosí: Facultad de Psicología de la Universidad Autónoma de San Luis Potosí. S.L.P, 2001.

ZILBERSTEIN, J. T.; OLMEDO, S. C. Didáctica desarrolladora: posición desde el enfoque histórico cultural. Educação e Filosofia, Uberlândia, v. 29, n. 57, p. 61-93. jan./jun. 2015.

Data de registro: $18 / 12 / 2018$

Data de aceite: $24 / 04 / 2019$ 